\title{
Pre-sowing magnetic field- induced changes in water relations and lipid peroxidation in cucumber under salinity stress
}

\author{
Ali Hassan Ibrahim \\ Received: 1 July 2016 / Accepted: 24 Sept. 2016 \\ Email: Ibrahim2910@yahoo.com
}

\begin{abstract}
Overcoming salinity problems through increasing plant tolerance is a substantial strategy to increase crop production. A pot experiment was carried out to investigate the effect of salinity stress, presowing magnetic fields and their combination on cucumber growth, water relations and lipid peroxidation. Seawater salinity $(10 \%)$ enormously reduced the plant growth, relative water content (RWC), transpiration rate and water use efficiency (WUE), and increased partial osmotic pressure (POP), lipids peroxidation and membrane injury index. Root/shoot ratio was not affected by the salinity stress.

Pre-sowing treatment with $50 \mathrm{mT}$ (for $30 \mathrm{~s}$ or $30 \mathrm{~min}$ ) and $100 \mathrm{mT}$ (30 min) magnetic field enhanced plant growth, root/shoot ratio, RWC, transpiration rate and WUE under control and stress conditions in relation with the un-treated plants. These treatments appeared to reduce lipid peroxidation and membrane injury in cucumber under salinity stress. The effect of these magnetic treatments on POP was not regular. The combination treatment of those magnetic fields and salinity reduced the stress intensity index (SII) by about $25 \%$ in relation with salinity alone. Conversely, the application of $200 \mathrm{mT}$ magnetic field for $30 \mathrm{~min}$ adversely affected the plant growth and water relations, and increased the SII, lipid peroxidation and membrane injury in cucumber under salinity stress. On many occasions, the effects of $100 \mathrm{mT}$ for $30 \mathrm{~min}$ and $200 \mathrm{mT}$ for $30 \mathrm{~s}$ were not significant.
\end{abstract}

Keywords: Dry mass - Lipid peroxidation- RWC-Stress index- transpiration-WUE.

\section{Introduction}

Salinity is a major constraint for agricultural crops in many regions, whereas it affects about $7 \%$ of total world land (Flowers and Yeo 1995, Shrivastava and Kumar 2015). The problems of salinity are most obvious in arid and semi-arid areas due to insufficient rainfall to move accumulated salts from root zone (Bresler et al. 1982). Salinity may be slight when total dissolved salt (TDS) concentrations is $1000-3000 \mathrm{ppm}$ or moderate as TDS is between $3000-10000 \mathrm{ppm}$ or high with TDS > 10000 ppm (Kanga and Jacksona 2016). Salinity stress restricts plant growth and productivity, and consequently contributes for the increased human famine (Abd EL-Kader et al. 2006). The adverse effects of this abiotic stress on crop plants are attributed to the osmotic effect and the specific ions effect (ions toxicity to various physiological process). Furthermore, increased exchangeable $\mathrm{Na}^{+}$can lead to soil swelling and dispersion, and root penetration problems (Bresler et al. 1982).

Egypt suffers from severe salinity problems due to low precipitation, irrigation with low quality water and high levels of underground water, whereas about of $33 \%$ of the agricultural land is already salinized (Hamam and Negim 2014, Wassef and Schüttrumpf 2016). By the 
end of $20^{\text {th }}$ century, about half of the consumed grains in Egypt was imported (Hinman and Hinman 1992), so alleviating salinity problems is a main target for Egyptian scientists to meet the country's over population. One of the primary strategies to overcome salinity problems is by increasing salt tolerance of plants. This can be achieved through traditional plant breeding or by producing transgenic plants which are salt tolerant. However, the progress to develop such plants is very slow due to the complex nature of salt tolerance (multigenic control) and high cost (Dionisio-Sese and Tobita, 2000, Iqbal and Ashraf, 2013).

An alternative way to increase salt tolerance in crops is by the usage of physical factors such as magnetic field. Application of magnetic field is safe, not expensive and friendly with the environment (Bhardwaj et al. 2012, Bilalis et al. 2013). On many occasions, the usage of this technology leads to an outstanding biochemical and biophysical changes which enhance seed germination, plant growth and crop productivity in both control and stress conditions (Dhawi 2014, Baghel et al. 2016). In this respect, Bilalis et al. (2013) found that pre-sowing treatment of cotton seeds with electromagnetic field for 15 and 30 min enhanced plant growth, transpiration rate, stomatal conductance, photosynthetic rate and contents of beneficial ions in relation with control plants. Conversely, the negative impact of magnetic field exposure on some plants was also recognized and was related to the accumulation of free radicals (Jouni et al., 2012). Such negative effect appeared to depend on the magnetic intensity and exposure period (Ibrahim 2015).

Cucumber is one of the most common horticultural crops in countries with a Mediterranean climate; however it is a salt sensitive crop (Chartzoulakis 1992). Application of magnetic field at specific intensity and exposure period enhanced seed germination, seedling growth and biochemical aspects in cucumber under control and salinity stress conditions (Bhardwaj et al. 2012, Ibrahim 2015). However, no information are available about the interactive effect of seeds magnetization and salinity on water relations and lipids peroxidation in this species, at vegetative stage. So this work was undertaken to characterize the changes in cucumber growth, water relations, lipids peroxidation and cellular membrane injury in response to the pre-sowing magnetic field treatments, salinity stress and their combination.

\section{Materials and Methods}

\section{Seeds source:}

Cucumber seeds (Cucumis sativus L. var. Beit Alpha) were purchased from Al-Qunfudah shop of plant seeds, Al-Qunfudah governorate, Saudi Arabia. This variety is widely used by farmers in this area. Seeds viability was found to be about $90 \%$ as evaluated by germination test.

Electromagnetic fields application:

The seeds were sterilized with 5\% Clorox solution for $5 \mathrm{~min}$ and washed thoroughly with sterile distilled water several times. After that, the seeds were soaked for $8 \mathrm{~h}$ in distilled water. Then the seeds were allocated into 4 groups: $0.0,50 \mathrm{mT}$, $100 \mathrm{mT}$ and $200 \mathrm{mT}$ magnetic field intensities at $30 \mathrm{~s}$ or 30 min exposure period using Dia, Para and Ferromagnetism system at physics Department at Al-Qunfudah College, Umm Al-Qura University, Saudi Arabia. This system has two coils (turns number per coil $=250, \quad$ coil resistance $=0.6 \Omega$ ) and a DC power supply with variable output current used for the electromagnet. A Teslameter model 4060.50 (Frederiksen) was used to monitor the field strength produced between the two poles. Growing conditions:

The seeds of each group were sown in plastic pots (4 seeds per pot). Each pot $(15 \mathrm{~cm} \mathrm{~W} \times 20 \mathrm{~cm}$ L) contained $2.75 \mathrm{~kg}$ soil (2 sandy soil: 1 peatmos). All pots were transferred to a constructed greenhouse at Al-Qunfudah College, whereas the plant were exposed to natural day/night conditions. Average photoperiod (day/night) and minimum/maximum temperature were $11.5 / 12.5 \mathrm{~h}$ and $20 / 35^{\circ} \mathrm{C}$, respectively. All plants were irrigated with normal tap water $(\mathrm{EC}=$ $0.2 \mathrm{mS} / \mathrm{cm}$ ) for three weeks. During this period the plants were thinned to one plant per pot and inorganic fertilizer was added ( $1 \mathrm{~g} \mathrm{Ca}$ (NO3) 2 and $1 \mathrm{~g} \mathrm{~K} 2 \mathrm{HPO} 4$ per pot). After that, the pots of each group were divided into two subgroups; control and salinity stress (10\% Red seawater). The full strength of this seawater is known to has $\mathrm{Cl}$ (22.33\%), $\mathrm{Na}+(11.9 \%), \mathrm{Mg}+2(1.51 \%), \mathrm{K}+$ $(0.59 \%), \mathrm{Ca} 2+(0.49 \%), \mathrm{pH}$ of 8.1 and $\mathrm{EC}$ of $72.5 \mathrm{mS} / \mathrm{cm}$ (Al Moubaraki et al. 2015). The total pots number was 112 with 8 replicates for each treatment. The plants in either control or salinity stress conditions were irrigated to field capacity when soil moisture content decreased to $60 \%$ of its initial value. The experiment was ended when the control plants started flowering (45 days after seed sowing) and samples were taken for analysis of 
vegetative growth, water relations, and Estimation of water use efficiency:

biochemical aspects.

\section{Evaluated parameters}

\section{Determination of plant biomass:}

The plants were harvested and separated into shoots and roots which were oven dried at $80^{\circ} \mathrm{C}$ for $48 \mathrm{~h}$ and weighed.

Estimation of stress intensity index:

Stress intensity index was estimated using the formula originally used by Fischer and Murer (1978) with a simple modification. This modification includes substitution of grain yield with total plant biomass as follows:

Stress intensity index $(\mathrm{SII})=1-($ total biomass in stress condition/total biomass in control condition).

\section{Determination of leaf relative water content:}

Based on the method described by Yamasaki and Dillenburg (1999), leaf discs from the second fully developed leaf from shoot apex were immediately weighed to have fresh mass (FM). The discs were floated in distilled water for $24 \mathrm{~h}$ in closed Petri dishes under dim light at room temperature and reweighed to obtain fully turgid mass (TM). Then the samples were oven dried at 80 for $48 \mathrm{~h}$ to obtain dry mass (DM). The relative water content (RWC) was calculated using the formula: $\operatorname{RWC}(\%)=[(\mathrm{FM}-\mathrm{DM}) /(\mathrm{TM}-\mathrm{DM})] * 100$.

Measurement of osmotic pressure:

Leaf samples $(1 \mathrm{~g})$ were heated in deionized water at $90{ }^{\circ} \mathrm{C}$ for $1 \mathrm{~h}$. After that, centrifugation take place and supernatant volume was adjusted to 25 cm3. Then the electrical conductivity was assessed by a Mettler-Toledo conductivity meter. The following equation was used to estimate the partial osmotic pressure (POP):

$\mathrm{POP}($ bar $)=0.36 \times \mathrm{EC}(\mathrm{mmho} \mathrm{cm}-1)($ Bresler et al. 1982)

\section{Determination of transpiration rate:}

Transpiration rate was measured by the gravimetric method as described by Xin et al. (2008). The pots containing plants were tightly covered with polyethylene sheets at the level of shoot base and weighed (at 7 a.m.). After 12 hours (at 7 p.m.), the pots were re-weighed. The loss in pot weight was used to express the transpiration rate.
Water use efficiency (WUE) of whole plant was determined using the following formula: WUE $\mathrm{g} \mathrm{kg}-1=$ dry weight of final biomass/ total water consumed (Medrano et al. 2015)

\section{Assessment of lipid peroxidation:}

Fresh samples were homogenized in ethanol $(80 \%)$ and centrifuged at $6000 \mathrm{~g}$ for $10 \mathrm{~min}$. Malondialdehyde (MDA) content as a main product of lipid peroxidation in the supernatant was measured by the thiobarbituric acid (TBA) method of Heath and Packer (1968). In short, 1 $\mathrm{cm} 3$ of sample supernatant and an equal volume of TBA solution (0.65\% TBA in $20 \%$ trichloroacetic acid) were added to a test tube and heated at $95{ }^{\circ} \mathrm{C}$ for $24 \mathrm{~min}$ and cooled on ice. The developed colour was read at $532 \mathrm{~nm}$ and $600 \mathrm{~nm}$ using an UV-Vis spectrophotometer (APEL, PD303 UV). MDA concentration was calculated by the following equation:

MDA equivalents (nmol.cm-1) $=1000[($ Abs 532Abs $600 \mathrm{~nm}) / 155$ ]

\section{Estimation of membrane injury:}

Cell membrane injury was expressed as an index of injury (Id) and estimated as: $I d=(R s-R c / 1$ $R c) \times 100$, where Rs and $R c$ represent electrolyte leakage for stress and control treated tissues, respectively (Flint et al. 1967). The electrolyte leakage was determined by the method of Bajji et al. (2002).

\section{Statistical analysis}

A completely random and factorial design was employed during the experimental work. The data were recorded as means from 3 to 8 replicates. Analysis of variance (ANOVA) and least significance difference between means (LSD) were carried out using SPSS version 19 software. Correlation coefficients between the stress intensity index and all evaluated parameters under the stress conditions were also estimated.

\section{Results}

\section{Changes in growth parameters:}

The results in Table 1 show the effect of seed exposure to different magnetic intensities for $30 \mathrm{~s}$ on cucumber vegetative growth. Application of 50 
mT magnetic field increased number of leaves number, total plant biomass and shoot length (also root/ shoot ratio) by about $10 \%, 15 \%$ and $20 \%$, respectively compared to the values of nontreated plants. Seed exposure to $100 \mathrm{mT}$ induced non-significant increase in these growth parameters in comparison with the $50 \mathrm{mT}$ treatment. Pre-sowing treatment with $200 \mathrm{mT}$ non significantly affected the growth of cucumber plants in relation with the untreated plants $(0 \mathrm{mT}$ treatment).

Salinity stress $(10 \%$ seawater) reduced shoot length, number of leaves and total plant dry mass by about $25 \%, 30 \%$ and $50 \%$, respectively in comparison with control plants (0 salinity and 0 $\mathrm{mT})$. This clarified that plant dry mass was the most affected growth parameter. However, the root/shoot ratio was insignificantly affected by salinity stress. Pre-sowing treatment with 50 and $100 \mathrm{mT}$ for $30 \mathrm{~s}$ obviously enhanced cucumber vegetative growth under salinity stress condition. Results in table 1 showed that these treatments increased shoot length (also number of leaves), plant dry mass and root/shoot ratio by about $15 \%$, $20 \%$ and $25 \%$, respectively over the values of salinity stress only. Except for root/shoot ratio which was enhanced by about $15 \%$, almost all the evaluated growth parameters were not significantly affected by the application of 200 $\mathrm{mT}$ under salinity stress condition.

Table 1. Effect of pre-sowing treatment with magnetic field for 30 second on growth parameters of cucumber plants grown under salinity stress.

\begin{tabular}{cccccc}
\hline \multicolumn{2}{c}{ Treatments } & \multicolumn{4}{c}{ Growth parameters } \\
\hline Salinity & $\begin{array}{c}\text { Magnetic } \\
\text { field } \\
\text { intensity } \\
(\mathbf{m T})\end{array}$ & $\begin{array}{c}\text { Shoot } \\
\text { length } \\
(\mathbf{c m})\end{array}$ & $\begin{array}{c}\text { Leaves } \\
\text { no. }\end{array}$ & $\begin{array}{c}\text { Total } \\
\text { plant } \\
\text { dry } \\
\text { mass } \\
\text { (g) }\end{array}$ & $\begin{array}{c}\text { Root/ } \\
\text { Shoot } \\
\text { ratio }\end{array}$ \\
\hline 0.0 & - & $23.8 \mathrm{c}$ & $10 \mathrm{a}$ & $1.87 \mathrm{~b}$ & $0.23 \mathrm{c}$ \\
& 50 & $28.3 \mathrm{ab}$ & $11 \mathrm{a}$ & $2.06 \mathrm{a}$ & $0.28 \mathrm{~b}$ \\
& 100 & $29.5 \mathrm{a}$ & $11 \mathrm{a}$ & $2.25 \mathrm{a}$ & $0.29 \mathrm{~b}$ \\
$10 \% \mathrm{SW}$ & 200 & $26.5 \mathrm{~b}$ & $10 \mathrm{a}$ & $1.88 \mathrm{~b}$ & $0.23 \mathrm{c}$ \\
& - & $17.6 \mathrm{~d}$ & $7 \mathrm{~b}$ & $0.91 \mathrm{~d}$ & $0.24 \mathrm{c}$ \\
& 50 & $19.91 \mathrm{c}$ & $8 \mathrm{~b}$ & $1.12 \mathrm{c}$ & $0.30 \mathrm{~b}$ \\
& 100 & $20.0 \mathrm{c}$ & $8 \mathrm{~b}$ & $1.2 \mathrm{c}$ & $0.34 \mathrm{a}$ \\
& 200 & $18.1 \mathrm{~d}$ & $7 \mathrm{~b}$ & $0.93 \mathrm{~d}$ & $0.28 \mathrm{~b}$ \\
\hline
\end{tabular}

Values in each column with the same letter(s) are not significantly different at $\mathrm{P}>0.05$.

Data in Table 2 show the vegetative growth parameters of cucumber in response to seed exposure to different magnetic intensities for 30 min. These results indicated two main differences compared to the results for the seeds that were exposed to magnetic field for $30 \mathrm{~s}$ (Table 1). First, the treatment of $50 \mathrm{mT}$ enhanced the growth parameters of cucumber than their counterparts of $100 \mathrm{mT}$ under control and stress conditions.
Secondly, pre-sowing treatment with $200 \mathrm{mT}$ for 30 min adversely affected plant growth parameters in comparison to the untreated plants over all conditions.

\section{Changes in stress intensity index (SII):}

It can be seen from Figure 1 that seed pre-sowing treatments with $50 \mathrm{mT}$ and $100 \mathrm{mT}$ for $30 \mathrm{~s}$ reduced SII by $20 \%$ and $35 \%$, respectively.

Table 2. Effect of pre-sowing treatment with magnetic field for 30 minutes on growth parameters of cucumber plants grown under salinity stress.

\begin{tabular}{cccccc}
\hline \multicolumn{2}{c}{ Treatments } & \multicolumn{4}{c}{ Growth parameters } \\
\hline Salinity & $\begin{array}{c}\text { Magnetic } \\
\text { field } \\
\text { intensity }\end{array}$ & $\begin{array}{c}\text { Shoot } \\
\text { length } \\
(\mathbf{c m})\end{array}$ & $\begin{array}{c}\text { Leave } \\
\text { s no. }\end{array}$ & $\begin{array}{c}\text { Total } \\
\text { plant } \\
\text { dry mass } \\
(\mathbf{g})\end{array}$ & $\begin{array}{c}\text { Root/ } \\
\text { Shoot } \\
\text { ratio }\end{array}$ \\
\hline 0.0 & - & $22 . \mathrm{c}$ & $10 \mathrm{a}$ & $1.87 \mathrm{~b}$ & $0.23 \mathrm{~cd}$ \\
& 50 & $30.25 \mathrm{a}$ & $11 \mathrm{a}$ & $2.35 \mathrm{a}$ & $0.30 \mathrm{~b}$ \\
& 100 & $28.1 \mathrm{a}$ & $11 \mathrm{a}$ & $1.82 \mathrm{~b}$ & $0.25 \mathrm{c}$ \\
$10 \% \mathrm{SW}$ & 200 & $25.5 \mathrm{~b}$ & $10 \mathrm{a}$ & $1.67 \mathrm{c}$ & $0.22 \mathrm{~d}$ \\
& - & $17.6 \mathrm{e}$ & $7 \mathrm{~b}$ & $0.91 \mathrm{e}$ & $0.24 \mathrm{~cd}$ \\
& 50 & $19.5 \mathrm{~d}$ & $8 \mathrm{~b}$ & $1.2 \mathrm{~d}$ & $0.32 \mathrm{a}$ \\
& 100 & $18.9 \mathrm{~d}$ & $8 \mathrm{~b}$ & $0.96 \mathrm{e}$ & $0.28 \mathrm{~b}$ \\
& 200 & $15.7 \mathrm{e}$ & $7 \mathrm{~b}$ & $0.64 \mathrm{f}$ & $0.22 \mathrm{~d}$ \\
\hline
\end{tabular}

Values in each column with the same letter(s) are not significantly different at $\mathrm{P}>0.05$.

The usage of $200 \mathrm{mT}$ for $30 \mathrm{~s}$ non significantly affected the SII in relation with the untreated plants. Seeds exposure to $50 \mathrm{mT}$ and $100 \mathrm{mT}$ for 30 min decreased the SII in cucumber by about $30 \%$ and $6 \%$ (non significant effect), respectively. On the other hand, pre-sowing treatment with 200 $\mathrm{mT}$ for $30 \mathrm{~min}$ increased the SII by $30 \%$ over the values of the untreated plants $(0 \mathrm{mT})$. These results clarified that seeds magnetization with 50 $\mathrm{mT}$ for $30 \mathrm{~s}$ or $30 \mathrm{~min}$ and $100 \mathrm{mT}$ for $30 \mathrm{~s}$ increased the tolerance of cucumber plants to $10 \%$ seawater stress, whereas the $200 \mathrm{mT}$ treatment for 30 min decreased this tolerance.

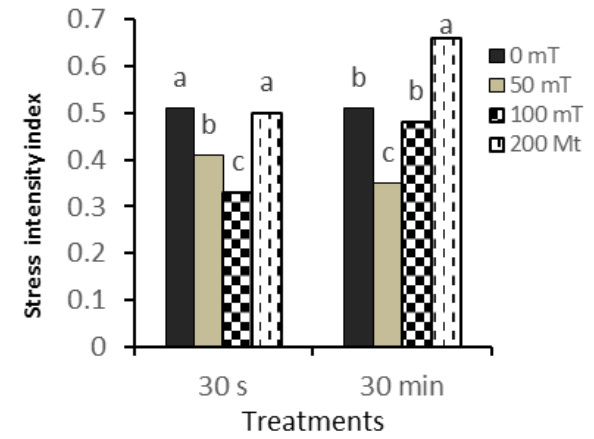

Fig. 1. Effect of electromagnetic fields on the stress intensity index in cucumber plants grown under salinity stress at 45 DAS. Values in a group with the same letter (s) are not significantly different at $\mathrm{P} \leq 0.05$. Abbreviation: DAS, days after sowing. 


\section{Changes in relative water content and osmotic pressure:}

The results for the changes in relative water content (RWC) of the $2^{\text {nd }}$ upper well developed leaf are shown in Figure 2A. In control condition, seed pre-sowing treatments with different magnetic fields for $30 \mathrm{~s}$ or $30 \mathrm{~min}$ non significantly affected the RWC in cucumber plants in comparison with the untreated plants. Salinity stress lowered the RWC by $30 \%$ than the control $(0 \mathrm{mT})$. Under salinity stress conditions, the treatment of $50 \mathrm{mT}$ and $100 \mathrm{mT}$ for $30 \mathrm{~s}$ or $30 \mathrm{~min}$ enhanced the RWC by about 20\% (for each). However, these values did not compensate with control values. Application of $200 \mathrm{mT}$ for $30 \mathrm{~s}$ slightly enhanced the RWC under salinity stress in relation with the untreated plants and the vice versa was observed at $30 \mathrm{~min}$ exposure.

It can be noted from Figure 2B that all magnetic treatments for $30 \mathrm{~s}$ or $30 \mathrm{~min}$, in general, non- significantly affected the estimated partial osmotic pressure (POP) in cucumber in relation with the untreated plants $(0 \mathrm{mT})$.

\section{Discussion}
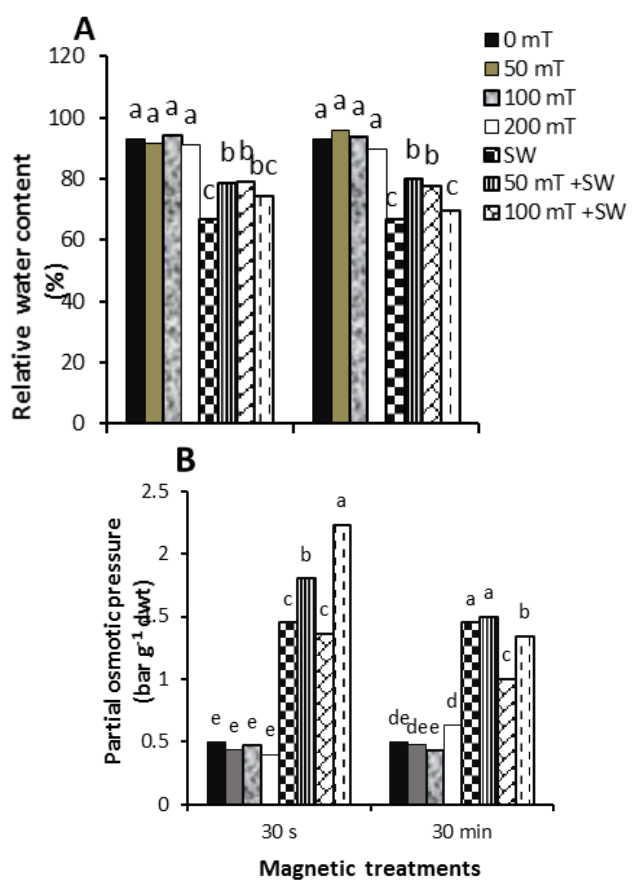

Fig. 2. Effect of pre-sowing treatment with magnetic field for 30 second and 30 minutes on RWC and osmotic pressure in cucumber plants grown under salinity stress at 45 DAS. Values in a group with the same letter (s) are not significantly different at $\mathrm{P} \leq 0.05$. Abbreviation: DAS, days after sowing.
There was a two-fold increase in the POP of plant leaves in response to salinity stress. Under salinity stress, the effect of magnetic treatments was not regular and on some occasions its value depended on the magnetic intensity and the exposure period. For example the treatment $50 \mathrm{mT}$ significantly increased the POP with $30 \mathrm{~s}$ exposure period and had a non-significant effect with 30 min exposure period in relation with the untreated plants

\section{Changes in transpiration rate and water use efficiency:}

Figure 3A shows the effect of salinity stress, magnetic fields and their interaction on cucumber transpiration rate. Salinity stress reduced transpiration rate in cucumber by about $60 \%$ below control values. Seed pre-sowing treatment with $50 \mathrm{mT}$ and $100 \mathrm{mT}$ for either $30 \mathrm{~s}$ or $30 \mathrm{~min}$ enhanced the transpiration rate in cucumber under control and salinity stress conditions by about $18 \%$. On many occasions, the application of 200 $\mathrm{mT}$ magnetic field had non-significant effect on the transpiration rate in either control or stress conditions.

Seawater stress (10\%) reduced WUE in cucumber by $40 \%$ in relation with control values $(0 \mathrm{mT})$. Application of $50 \mathrm{mT}$ for $30 \mathrm{~s}$ or $30 \mathrm{~min}$, and $100 \mathrm{mT}$ for $30 \mathrm{~s}$ mitigated the adverse effect of salinity stress.

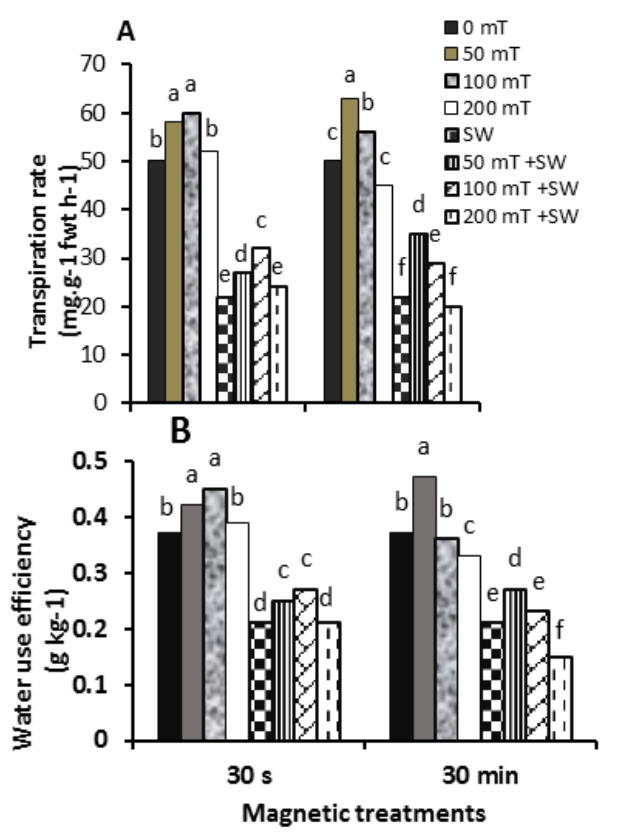

Fig.3. Effect of pre- sowing treatment with magnetic field for 30 second and 30 minutes on transpiration rate and WUE in cucumber plants grown under salinity stress at 45 DAS. Values in a group with the same letter (s) are not significantly different at $\mathrm{P} \leq 0.05$. Abbreviation: DAS, days after sowing. 
These treatments appeared to enhance the WUE (20\% increase) and the effect was more obvious under the stress conditions. On the other hand, the combination treatment of $200 \mathrm{mT}$ for $30 \mathrm{~min}$ and salinity stress added more reduction in WUE than the salinity alone (Figure 3B).

\section{Changes in lipid peroxidation and membrane injury index:}

The results presented in Figure 4 show the effect of seed magnetization on lipid peroxidation in cucumber under $10 \%$ seawater stress. Application of different magnetic fields $(50 \mathrm{mT}, 100 \mathrm{mT}$ and $200 \mathrm{mT}$ ) for 30 s did not virtually affect lipid peroxidation in cucumber under control conditions. Salinity stress increased lipid peroxidation by about $150 \%$ over the control values. The dual treatments of all magnetic fields for $30 \mathrm{~s}$ and salinity stress reduced this physiological aspect by about $25 \%$ in relation with salinity treatment alone. Except for $200 \mathrm{mT}$ seed treatment which enhanced lipid peroxidation, the results due to $30 \mathrm{~min}$ exposure period were comparable with those of $30 \mathrm{~s}$ exposure period.

On many occasions, the combination treatments of magnetic fields and salinity stress lowered the membrane injury index in cucumber than salinity alone (Fig.5). Pre-sowing treatments with $50 \mathrm{mT}, 100 \mathrm{mT}$ and $200 \mathrm{mT}$ magnetic field for $30 \mathrm{~s}$ decreased the cellular membrane injury index in cucumber by about $15 \%, 45 \%$ and $25 \%$, respectively. The results for $50 \mathrm{mT}$ and $100 \mathrm{mT}$ at 30 min exposure period did not greatly differ from those observed at $30 \mathrm{~s}$ exposure period, whereas the application of $200 \mathrm{mT}$ for $30 \mathrm{~min}$ non significantly decreased the membrane injury index in relation with salinity stress alone.

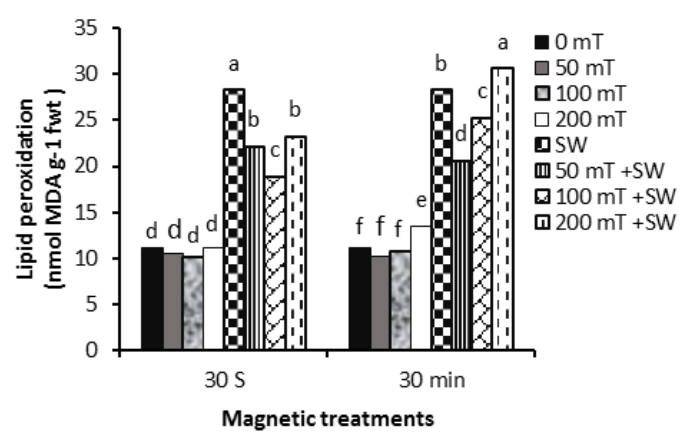

Fig. 4. Effect of pre-sowing treatment with magnetic field for 30 second and 30 minutes on lipid peroxidation in cucumber plants grown under salinity stress at 45 DAS. Values in a group with the same letter (s) are not significantly different at $\mathrm{P} \leq 0.05$. Abbreviation: DAS, days after sowing.
Under control conditions, the values of this index were also reduced in response to most magnetic treatments.

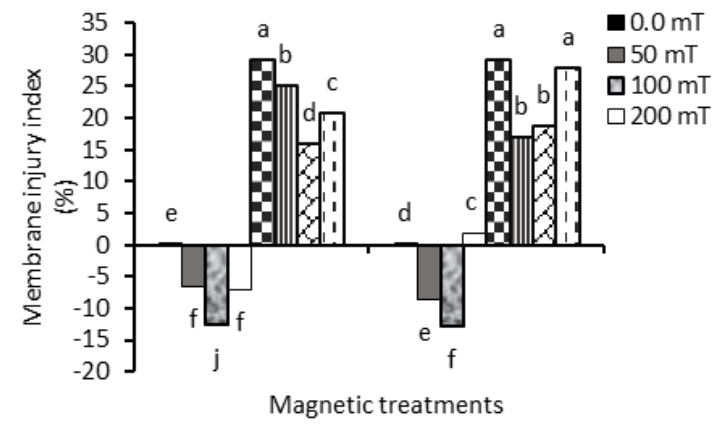

Fig. 5. Effect of pre- sowing treatment with magnetic field for 30 second and 30 minutes on membrane injury index in cucumber plants grown under salinity stress at 45 DAS. Values in a group with the same letter (s) are not significantly different at $\mathrm{P} \leq 0.05$. Abbreviation: DAS, days after sowing.

\section{Correlation coefficients between SII and the evaluated parameters:}

The estimated stress intensity index as an indication of plant susceptibility based on total dry mass, under salinity stress, had a strong negative correlation with shoot length, biomass, root/shoot ratio, transpiration rate and water use efficiency $[\mathrm{r}$ $=-(0.93-0.99) ;$ Table 3]. Conversely, a strong positive correlation manifested between the SII and lipid peroxidation $(\mathrm{r}=0.91)$. A modest correlation appeared with RWC $(r=-0.74)$ and membrane injury index $(r=0.70)$. The partial osmotic pressure of leaves had non-significant correlation with the SII (Table 3).

Table 3. Correlation coefficients between stress intensity index (SII) and the evaluated parameters in cucumber under salinity stress.

\begin{tabular}{lcc}
\hline Parameters & Correlation coefficient with SII (r) \\
\hline Shoot length & - & $0.95^{* *}$ \\
Total dry mass & - & $0.99 * *$ \\
Leaves number & - & $0.77^{*}$ \\
Root/shoot ratio & - & $0.93^{* *}$ \\
Relative water content & - & $0.74 *$ \\
Partial osmotic pressure & & 0.008 \\
Transpiration rate & - & $0.88 * *$ \\
Water use efficiency & - & $0.99 * *$ \\
Lipid peroxidation & & $0.91 * *$ \\
Membrane injury index & $0.70^{*}$
\end{tabular}

*, ** indicate significance at $\mathrm{p}<0.05$ and 0.01 , respectively. 


\section{Discussion}

During the last decade, a great attention has been offered to the magnetic field application as a possible strategy to improve plant growth and productivity under environmental stress conditions. In this study, the notable reduction in cucumber growth under $10 \%$ seawater salinity confirmed that this species is sensitive to salinity stress and this level of salinity is critical (50\% total biomass reduction) for its growth. These results are compatible with the findings of Khan et al. (2013) that $5 \mathrm{dS} \mathrm{m}^{-1}$ salinity stress adversely affected cucumber dry mass, shoot length and number of leaves. The non- significant effect of the used stress on root/shoot ration was also reported by Al-Harbi and Burrage (1993). This indicates that the allocation of dry mass to root system did not enhance under salinity stress, a reason which could contribute to cucumber sensitivity under salinity stress. In contrast to our results, this ratio was found to increase in salinity tolerant cultivars and halophytes under saline conditions (Albacete et al. 2010, Ibrahim 2013).

The observed reduction in RWC and transpiration rate in cucumber under salinity stress are expected results and could be related to the decrease of root absorption capacity and clarified that the salinity resulted in cellular dehydration and stomatal closure (Wang et al.2006, Qin et al. 2010). This water imbalance led to the reduction in plant water use efficiency in cucumber under stress conditions (Wang et al. 2006). The demonstrated increased in lipid peroxidation and membrane injury in response to $10 \%$ seawater stress could be attributed to the increment of free radicals which is widely observed under salinity stress (Furtana and Tipirdamaz 2010). It is appeared from the obtained results that the reduction in RWC and transpiration rate as well as the increase in lipid peroxidation and membrane injury resulted in the reduction in plant growth under salinity stress. Others, attributed this reduction to the osmotic effect of salinity and/ or the increase in tissue $\mathrm{Na}^{+}$which replaces $\mathrm{K}^{+}$ion (Munns and Tester, 2008).

The stimulative effect of pre-sowing magnetic field with the intensity of $50 \mathrm{mT}$ and 100 $\mathrm{mT}$ at exposure periods of $30 \mathrm{~s}$ or $30 \mathrm{~min}$, on many occasions, on cucumber growth under control and salinity stress was also observed in many other plants (Radhakrishnan and Kumari, 2012 and Azimian and Roshande, 2015). In this regard, Rãcuciu et al. (2008) found that the cultivation of Zea mays germinated seeds under $50 \mathrm{mT}$ static magnetic field for 14 days greatly enhanced growth parameters and chlorophyll content in relation with non treated plants. This improvement under saline conditions and consequently the reduction in stress intensity index can be related to the amelioration in root/ shoot ratio, RWC and transpiration rate, and to the reduction in lipid peroxidation which enhanced the cellular membrane stability. In support of our result, Bilalis et al. (2013) found pre-sowing treatment with magnetic fields for 15 and 30 minutes enhanced plant growth, transpiration rate, stomatal conductance and photosynthetic rate in cotton. It is worth to mention that the actual mechanisms by which magnetic field enhances plant growth are poorly understood. However, growing evidences suggest that magnetic field application increase the physiological availability of small ions such as $\mathrm{Ca}^{2+}$ and $\mathrm{K}^{+1}$ which regulates many cellular processes, and water mobility due to the decrease in water viscosity and surface tension (Xiao-Fenga and Boa 2008, Pazur and Rassadina 2009).

The observed adverse effect of $200 \mathrm{mT}$ magnetic intensity for $30 \mathrm{~min}$ exposure period on cucumber growth under control and stress condition is compatible with the results of Rãcuciu et al. (2008) that 150- $200 \mathrm{mT}$ magnetic field negatively affected Zea mays growth and chlorophyll content. This reduction was associated with an increase in the stress intensity index and can be attributed to the demonstrated increase in lipid peroxidation and cellular membrane injury, and the decrease in RWC and transpiration rate. Contrary to our results, Baghel et al (2016) found the enhancement effect of seed pre-treatment with $200 \mathrm{mT}$ magnetic field on soybean growth and metabolism under both saline $(25$ and $50 \mathrm{mM}$ $\mathrm{NaCl}$ ) and non saline conditions. This difference in response indicates the difference in sensitivity to magnetic field between different species.

\section{Conclusion}

The application of $10 \%$ seawater stress significantly reduced the growth parameters in cucumber plants, except for root/shoot ratio which did not change. This stress imbalance the plant water status and induce lipid peroxidation and membrane injury. Pre-sowing treatment with 50 $\mathrm{mT}$ (for $30 \mathrm{~s}$ and $30 \mathrm{~min}$ ) and $100 \mathrm{mT}$ (for $30 \mathrm{~s}$ ) magnetic fields partially alleviated the adverse effect of salinity stress on plant growth. This beneficial effect was accompanied with an 
enhancement in RWC, transpiration and WUE, and reduction in lipid peroxidation as well as membrane injury under stress conditions. On the other hand, the dual treatment of $200 \mathrm{mT}$ for 30 min with salinity stress added more adverse effect than salinity alone. So, magnetic field is a promising strategy to overcome salinity problems in cucumber, when it is used at the appropriate intensity and exposure period.

\section{Acknowledgements}

Great thanks to Dr. A. M. Abdul-Kader the head of Physics Department (Al-Qunfudah University College, SA) for giving us the chance to use the ferromagnetism apparatus.

\section{References}

Abd EL-Kader A. A, Mohamedin A.A.M. and Ahmed M.K.A (2006). Growth and yield of sunflower as affected by different Salt affected Soils. Int. J. Agri. Biol. 8 (5): 583-587.

Albacete A., Ghanem M.E. , Martínez-Andújar C., Acosta M. et al. (2008). Hormonal changes in relation to biomass partitioning and shoot growth impairment in salinized tomato (Solanum lycopersicum L.) plants. J. Exp. Bot. 59 (15): 41194131.

Al-Harbi, A.R. and Burrage, S.W. (1993). Effect of $\mathrm{NaCl}$ salinity on growth of cucumber Cucumuis sativus L. grown in NFT. Acta Hortic. 323: 39-50.

Al-Moubaraki A. H., Al-Judaibi A and Asiri M (2015). Corrosion of C-steel in the red sea: Effect of immersion time and inhibitor concentration. Int.J. Electrochem.Sci. 10: 4252-4278.

Azimian F. and Roshande P. (2015). Magnetic field effects on total phenolic content and antioxidant activity in Artemisia sieberi under salinity. Ind. J. Plant Physiol. 20 (3): 264-270.

Baghel, L., Kataria, S. and Guruprasad, K. N. (2016). Static magnetic field treatment of seeds improves carbon and nitrogen metabolism under salinity stress in soybean. Bioelectromagnetics. doi:10.1002/bem.21988.

Bajji M., Kinet J.M, Lutts S. (2002). The use of the electrolyte leakage method for assessing cell membrane stability as a water stress tolerance test in durum wheat. Plant Growth Regul. 36: 61-70.

Bhardwaj J., Anand A., Nagarajan S. (2012). Biochemical and biophysical changes associated with magneto priming in germinating cucumber seeds. Plant Physiol. Biochem. 57: 67-73.Bilalis,
D. J., Katsenios N., Efthimiadoun A., Karkanis A., Khah E. M., and Mitsis T. (2013). Magnetic field pre-sowing treatment as an organic friendly technique to promote plant growth and chemical elements accumulation in early stages of cotton. Aust. J. Crop Sci. 7 (1):46-50.

Bresler E., McNeal B.I., Carter D.L. (1982). Saline and Sodic Soils: Principles-Dynamics-Modeling. Springer-Verlag, Berlin.

Chartzoulakis, K. S. (1992). Effects of $\mathrm{NaCl}$ salinity on germination, growth and yield of green house cucumber. J. Hortic. Sci. 67: 115- 119.

Dhawi F. (2014). Why magnetic fields are used to enhance a plant's growth and productivity?. Annu. Res. Rev. Biol. 4 (6): 886-896.

Dionisio-Sese M. D. and Tobita S. (2000). Effects of salinity on sodium content and

photosynthetic responses of rice seedlings differing in salt tolerance. J. Plant Physiol. 157:5458.

Fischer R.A. and Murer R. (1978) Drought resistance in spring wheat cultivars. I. Grain yield response. Aust. J. Agric. Res. 29: 897-912.

Flint H.L., Boyce B.R. and Beattie D.J. (1967). Index of injury - A useful expression of freezing injury to plant tissues as determined by the electrolytic method. Can. J .Plant. Sci. 47: 229-230.

Flowers, T. J. and Yeo A. R. (1995). Breeding for salinity resistance in crop plants: where next?. Aust. J. Plant. Physiol. 22: 875-884.

Furtana G. B. and Tipirdamaz R. (2010). Physiological and antioxidant response of three cultivars of cucumber (Cucumis sativus L.) to salinity. Turk. J. Biol 34: 287-296.

Hamam K.A. and Negim O. (2014). Evaluation of wheat genotypes and some soil properties under saline water irrigation. Ann. Agric. Sci. 59(2): 165176.

Heath R.L. and Packer L. (1968) Photoperoxidation in isolated chloroplast. I. Kinetics and stoichiometry of fatty acid peroxidation. Arch. Biochem. Biophys. 125:189-198.

Hinman W. and Hinman J. (1992). The plight and promise of arid land agriculture. Columbia University Press, New York.

Ibrahim (2013). Tolerance and avoidance responses to salinity and water stresses in Calotropis procera and Suaeda aegyptiaca Turk. J. Agric. For. 37: 352360

Ibrahim A H (2015). Influence of different intensities of magnetic field on germination, vegetative growth and some physiological aspects of salinity-stressed cucumber. Catrina 10 (1): 93 -101.

Iqbal, M., and Ashraf M. (2013). Gibberellic acid mediated induction of salt tolerance in wheat plants: Growth, ionic partitioning, photosynthesis, yield 
and hormonal homeostasis. Environ.. Exp. Bot. $86: 76-85$

Jouni, F. J., Abdolmaleki P., and Ghanati F. (2012). Oxidative stress in broad bean(Vicia faba L.) induced by static magnetic field under natural radio activity. Mutat. Res. 741:116 - 121 .

Kanga M. and Jacksona R. B. (2016). Salinity of deep groundwater in California: Water quantity, quality, and protection. PNAS 113(28): 7768-7773.

Khan M. M, Al-Mas'oudi R. S. M., Al-Said F. and Khan I. (2013). Salinity Effects on Growth, Electrolyte Leakage, Chlorophyll Content and Lipid Peroxidation in Cucumber (Cucumis sativus L.). Int. Conf. Food Agri. Sci. IPCBEE Singapore 55: 28-32.

Medrano H., Tomása M., Martorella S., Flexasa J., Hernándeza E., Rossellóa J., Poub A, Escalonaa JM., Bota J. (2015). From leaf to whole-plant water use efficiency (WUE) in complex canopies: Limitations of leaf WUE as a selection target. The Cop J. 3: 220-228.

Munns R. and Tester M. (2008). Mechanisms of salinity tolerance. Annu. Rev. Plant Biol. 59: 651681.

Pazur A. and Rassadina V. (2009). Transient effect of weak electromagnetic fields on calcium ion concentration in Arabidopsis thaliana. BMC Plant Biol. 9 : 1-9

Qin J., Dong W.Y., He K.N., Yu Y. et al. (2010). NaCl salinity-induced changes in water status, ion contents and photosynthetic properties of Shepherdia argentea (Pursh) Nutt. Seedlings. Plant Soil Environ. 56: 325-332.

Rãcuciu M., Creangã D. and Horga I. (2006). Plant growth under static magnetic field influence. Rom. J. Phys., 53 ( 1-2): 353-359.

Radhakrishnan R. and Kumari B. D. R. (2012). Stress. Pulsed magnetic field: A contemporary approach offers to enhance plant growth and yield of soybean. Plant Physiol. Biochem. 51: 139-144.

Shrivastava P. and Kumar R. (2015). Review: Soil salinity: A serious environmental issue and plant growth promoting bacteria as one of the tools for its alleviation. Saudi J. Biol. Sci. 22: 123-131.

Wang S., Guo S., Li J., Hu X. and Jiao Y. (2006). Effects of salt stress on the root growth and leaf water use efficiency of cucumber seedlings. Ying Yong Sheng Tai Xue Bao (J. Appl. Ecol.) 17(10):1883-8. Chinese.

Wassef R. and Schüttrumpf H. (2016). Impact of sealevel rise on ground water salinity at the development area western delta, Egypt. Groundwater Sustain. Dev. 2-3: 85-103.

Xiao-Fenga P. and Boa D. (2008) The changes of macroscopic features and microscopic structures of water under influence of magnetic field. Physica B 403: 3571- 3577.

Xin Z., Franks C., Payton P., Burke J.J. (2008). A simple method to determine transpiration efficiency in sorghum. Field Crops Res. 107: 180-183

Yamasaki S. and Dillenburg L. R. (1999). Measurements of leaf relative water content in Araucaria angustifolia. Rev. Bras. Fisiol. Veget. 11(2):69-75 
الملخص العربي

عنوان البحث: التغيرات المستحثة بالمجال المغناطيسى قبل البذر فى العلاقات المائية والأكسدة الفوقية للاهون فى الخيار تحت الإجهاد الملحى نباتات التفرات المبات

على حسن ابراهيم1

1 قسم النبات ـ كلية العوم -جامعة بورسعيد

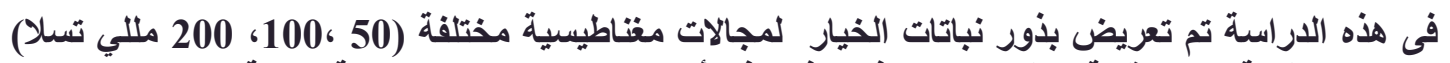

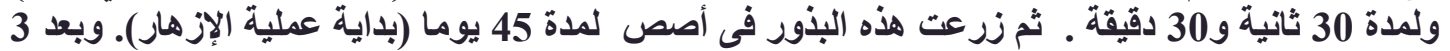

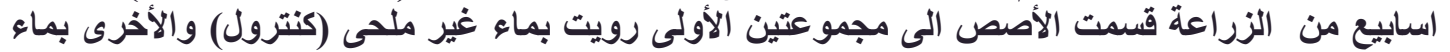

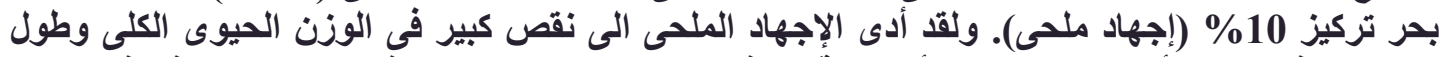

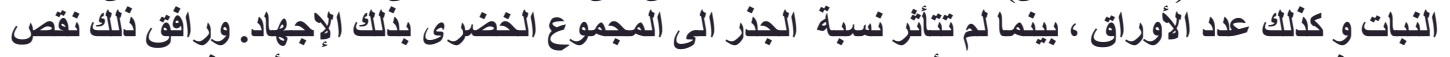

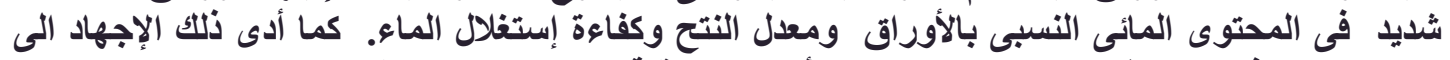

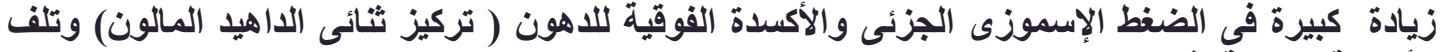

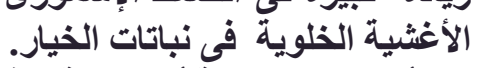

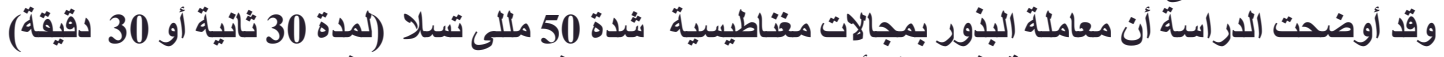

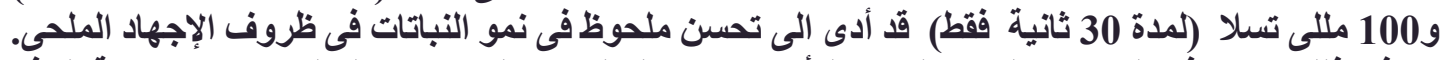

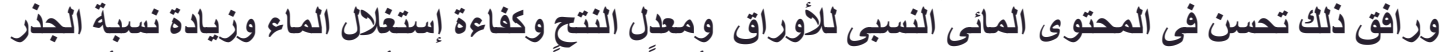

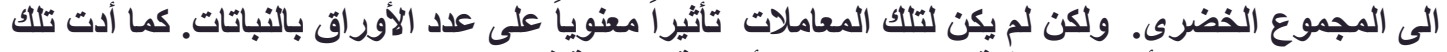

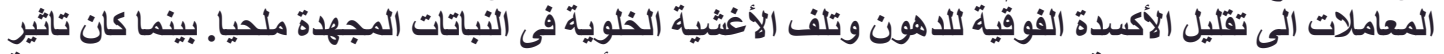

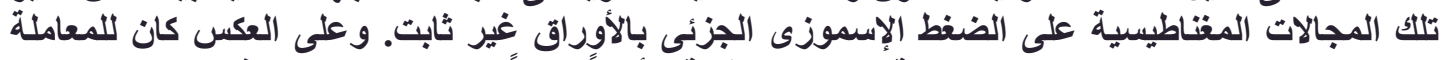

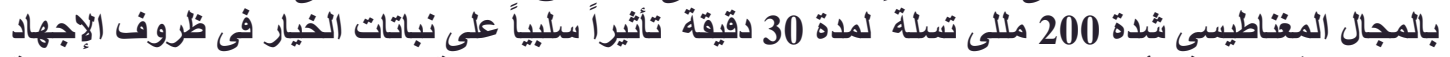

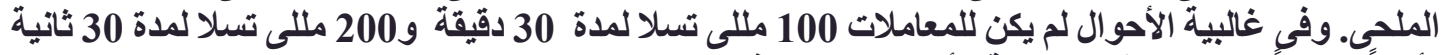
تأثيرا معنوياً على العلاقات المائية وأكسدة الدهون فى نباتات الخيار. 